\title{
Is this patient really "(un)stable"? How to describe cardiovascular dynamics in critically ill patients
}

\author{
Jean-Louis Vincent ${ }^{1 *}$ (D), Maurizio Cecconi ${ }^{2}$ and Bernd Saugel ${ }^{3}$
}

Earlier this week during rounds in the intensive care unit, a resident reported, "Mr S. became hemodynamically unstable so we had to give norepinephrine." Later, another resident described a patient with acute respiratory distress syndrome who had been on renal replacement therapy for the last $36 \mathrm{~h}$ as being, "hemodynamically stable under 1 $\mu \mathrm{g} / \mathrm{kg} / \mathrm{min}$ of norepinephrine." This led us to reflect on the meanings of these two words-"stable" and "unstable"-when describing cardiovascular dynamics in critically ill patients.

The terms hemodynamically "stable" and "unstable" are used frequently but what do they actually mean? And are they appropriate or even correct? Can a critically ill patient ever really be accurately described as being stable or unstable? A stable condition can be defined as a situation that does not change substantially over time. But surely all critically ill patients are per se unstable as, by the very nature of being critically ill, their physiological variables-including cardiovascular dynamics-change frequently over time [1]. Although vital signs can appear stable when a patient is receiving organ support, the patient is still critically ill. Terminology in such patients needs to be precise, and vague descriptive terms should be avoided. Indeed, there are no generally accepted and uniform definitions of the conditions stable and unstable, and the same patient may be classified as stable or unstable by different doctors and nurses depending on their clinical judgment, experience, and knowledge of the patient's clinical course. In Fig. 1, we propose some clinical scenarios that demonstrate these problems with the use of the words "stable" and "unstable" when describing cardiovascular dynamics in critically ill patients.

\footnotetext{
* Correspondence: jlvincent@intensive.org

${ }^{1}$ Department of Intensive Care, Erasme Hospital, Université libre de Bruxelles,

1170 Brussels, Belgium

Full list of author information is available at the end of the article
}

So, how should we describe these patients? To the first resident, we suggested that Mr. S. who had become "hemodynamically unstable" had actually developed circulatory shock and that this was the preferred term. To further describe the cardiovascular dynamics in this and similar patients, available objective criteria (blood pressure, cardiac output, rate of vasopressor or inotrope) should be used.

For the second resident, the problem is perhaps more related to interpretation than definition. The word "stable" often has positive connotations when used to refer to patient condition. When the resident described his patient as "being stable," everyone agreed, knowing that this meant there had been no acute change in the patient's condition or treatment. In fact, the patient still had profound circulatory shock. Using the word "stable" in such patients may even create a false sense of security for the care team, such that they begin to accept the critical state of the patient as "normal" and lessen efforts to try and resolve the serious condition. Additionally in this case, when the relatives called anxiously to get some news and the nurse said "the situation is stable," this gave them the impression that their loved one was not getting worse, thus offering them some hope of recovery. Without further more detailed explanation, relatives may not understand that being stable in such critical conditions actually means the patient is not getting better and his/her chances of a positive outcome are likely getting worse. Indeed, the duration of shock is an important prognostic factor [2, 3].

Although widely used among physicians and frequently present in the literature, the words "stable" and "unstable" to describe cardiovascular dynamics in critically ill patients can have different meanings to different people and in different situations, making them confusing word choices that should be avoided. We must be careful and precise with our choice of words to colleagues, patients, and families and avoid 
Is this patient:

stable? unstable?

In a patient who is being treated in the ICU after a suicide attempt with benzodiazepines, the mean arterial pressure increases abruptly from 70 $\mathrm{mmHg}$ to $100 \mathrm{mmHg}$ each time he wakes up (no vasoactive agents)

In a patient who was just admitted to the ICU after major abdominal surgery, the systolic blood pressure has dropped from $120 \mathrm{mmHg}$ to 70 $\mathrm{mmHg}$ within 10 minutes

In a patient treated for intraabdominal sepsis with multiple organ failure, the mean arterial pressure has been around $65 \mathrm{mmHg}$ under 0.8 to $1.1 \mathrm{\mu g} / \mathrm{kg} / \mathrm{min}$ of norepinephrine for the last two days

(tick the most appropriate box)

The blood pressure goes up and down in an ICU patient on 0.05 $\mu \mathrm{g} / \mathrm{kg} / \mathrm{min}$ of norepinephrine after intracranial surgery

Fig. 1 What is hemodynamic (in)stability

vague terms that could be misinterpreted. The word "stable" should not be used to describe a condition that remains critical, and "hemodynamic instability" should be described using objective criteria such as blood pressure, cardiac output, or vasopressor dose.

\section{Acknowledgements}

None.

\section{Authors' contributions}

JLV wrote the first draft. MC and BS critically revised the content. All authors read and approved the final manuscript before submission.

\section{Funding}

None.

Availability of data and materials

Not applicable.

\section{Ethics approval and consent to participate}

Not applicable.

\section{Consent for publication}

Not applicable.

\section{Competing interests}

JLV is the Editor-in-Chief of Critical Care. He has no other conflicts of interest to declare related to this manuscript. The other authors declare that they have no competing interests.

\section{Author details}

'Department of Intensive Care, Erasme Hospital, Université libre de Bruxelles, 1170 Brussels, Belgium. ${ }^{2}$ Department of Anesthesia and Intensive Care Units, Humanitas Research Hospital, 20089 Milan, Italy. ${ }^{3}$ Department of

Anesthesiology, Center of Anesthesiology and Intensive Care Medicine, University Medical Center Hamburg-Eppendorf, 20246 Hamburg, Germany.

Received: 6 April 2019 Accepted: 23 July 2019

Published online: 06 August 2019

\section{References}

1. Frost $\mathrm{P}$, Wise MP. Recognition and early management of the critically ill ward patient. Br J Hosp Med (Lond). 2007:68:M180-3.

2. Vincent JL, Nielsen ND, Shapiro NI, et al. Mean arterial pressure and mortality in patients with distributive shock: a retrospective analysis of the MIMIC-III database. Ann Intensive Care. 2018;8:107.
3. Maheshwari K, Nathanson BH, Munson SH, et al. The relationship between ICU hypotension and in-hospital mortality and morbidity in septic patients. Intensive Care Med. 2018;44:857-67.

\section{Publisher's Note}

Springer Nature remains neutral with regard to jurisdictional claims in published maps and institutional affiliations. 